\title{
Tables, Figures and Photos
}

\section{Tables}

Table 4.1 Classical theories of emotion 68

Table 4.2 Key themes of tourism research related to emotions

\section{Figures}

Figure I.1 The philosophy of tourism: Giving and receiving within the act of travel for tourism purposes

Figure 1.1 How high-quality standards of service overlap with the qualities of hospitality

Figure 1.2 How organisational culture promotes core commercial values to the detriment of philoxenia

Figure 1.3 How tourists' unethical and/or egoistical actions influence philoxenia

Figure 1.4 How employees' inappropriate and impolite actions influence the offering of philoxenia

Figure 2.1 Agape and its actions

Figure 3.1 Philanthropy in tourism and hospitality

Figure 4.1 Intensity of human interactions and spaces influencing emotional states

Figure 4.2 Conceptualising the tourism and emotions nexus

$\begin{array}{lll}\text { Figure 5.1 Well-being and perspectives } & 80\end{array}$

$\begin{array}{ll}\text { Figure 5.2 Ways of understanding happiness } & 83\end{array}$

Figure 5.3 The well-being and tourism experiential matrix 89

Figure 5.4 The nexus of tourism and happiness 91

Figure 6.1 The linkage of enclaved tourism areas, liminality and carnivalesque behaviour 97

Figure 6.2 Tourism and overconsumption 106

Figure 7.1 Place in the context of tourism 122 


\section{Photos}

Photo I.1 Athens, Greece 5

Photo 1.1 Visitors at Alexander Nevsky Cathedral, Tallinn, Estonia 24

Photo 2.1 Sanctuary, Victoria, Australia 39

Photo 2.2 Giraffe Centre, Kenya 42

Photo 3.1 Christmas charity trees at a resort in Orlando, USA 49

Photo 3.2 Bran Castle, Transylvania, Romania 56

$\begin{array}{lll}\text { Photo 4.1 Venice resort, Macau } & 60\end{array}$

Photo 4.2 Smurf village, Belgium 61

Photo 4.3 Seaplane Harbour, Estonian Maritime Museum, Estonia 62

Photo 4.4 Sovereign Hill, Ballarat, Australia 64

$\begin{array}{lll}\text { Photo 4.5 Landscape, Iceland } & 66\end{array}$

$\begin{array}{ll}\text { Photo 4.6 Island of Ithaca, Greece } & 73\end{array}$

Photo 5.1 Prague, Czech Republic 79

Photo 5.2 Mini-Europe theme park, Belgium 81

$\begin{array}{lll}\text { Photo 6.1 Tropical beach, Thailand } & 100\end{array}$

Photo 6.2 Food market, Stockholm, Sweden 101

$\begin{array}{lll}\text { Photo 7.1 Phuket Island, Thailand } & 116\end{array}$

Photo 8.1 Mount Athos, Greece 128

Photo 8.2 Old Jewish Cemetery, Prague, Czech Republic 130

Photo 8.3 'Nea Moni', UNESCO World Heritage Site, Island of Chios, Greece 133

Photo 8.4 Piazza di San Pietro, Vatican City 135 